\title{
Metáfora e gramática: a categorização de um fenômeno multifacetado
}

\author{
Metaphor and grammar: the categorization of a \\ multifaceted phenomenon
}

\author{
Marina Chiara Legroski**
}

\begin{abstract}
RESUMO: Este trabalho pretende fazer uma revisão do tratamento dado à metáfora nas gramáticas tradicionais, de cunho normativista, e nas gramáticas contemporâneas, que se pretendem descritivistas. Esta revisão se baseia no pressuposto linguístico de que a metáfora não é um uso especial da linguagem, mas um mecanismo linguístico disponível e utilizado pelos falantes o tempo todo. Desta forma, investigamos o surgimento da metáfora dentro dos estudos gramaticais e a parca modificação da abordagem deste fenômeno ao longo dos tempos. Como dissemos, entendemos que a metáfora não faz parte de uma classe gramatical específica - e nem faria sentido pensar desta forma - e, assim, este trabalho olha para as categorizações disponíveis a fim de propor uma nova maneira de tratá-la, mais condizente com o rumo seguido pela linguística moderna.
\end{abstract}

PALAVRAS-CHAVE: Metáfora. Gramática. Classes gramaticais.

ABSTRACT: This paper intends to do a revision of the metaphor accounts given by the traditional grammars, with a normative bias, and the contemporary ones, which are aimed as descriptive. This revision have basis on the linguistic presupposition that the metaphor is not a language special use, but a linguistic mechanism available and used by the speakers all the time. Therefore, we investigate the early studies of metaphor within the grammar studies and the limited modification of this phenomenon's account along the time. As we just said, we understand that the metaphor does not belong to a specific grammar class - nor would make sense to think that way - and, thus, this paper focuses on the available categorizations in order to propose a different way to account it, more consistent with the course of modern linguistics.

KEYWORDS: Metaphor. Grammar. Grammar classes.

A metáfora faz parte das preocupações linguísticas desde a Antiguidade Clássica, pelo menos desde que Aristóteles falou sobre ela em $A$ poética.

*Doutoranda do programa de Pós-Graduação em Letras da Universidade Federal do Paraná.

Bolsista CAPES. E-mail: marinalegroski@gmail.com. 
(ARISTÓTELES, 1993). Como na antiguidade clássica filosofia e gramática andavam intimamente ligadas, desde então, a metáfora vem sendo tratada como uma figura de linguagem, um "desvio" do uso corriqueiro de uma palavra, que continua nas gramáticas mais por uma questão histórica do que propriamente como classificação de um tipo diferente de palavras, uma vez que podem ser metafóricos os usos de palavras pertencentes a diferentes classes gramaticais (nomes, verbos, advérbios e mesmo preposições, como veremos adiante).

Sendo assim, na tradição gramatical, "metáfora" não é o nome de uma categoria de palavras, como são "verbos", "substantivos", "pronomes", mas o nome de um processo semântico que faz com que uma palavra seja utilizada com um significado diferente do seu significado "primeiro" ou "original". Ela, junto com fenômenos como metonímia, antítese e aliteração, figura na seção destinada às "figuras de linguagem" de uma gramática.

Da mesma forma que a tradicional nomenclatura de classes coagiu o pensamento linguístico ocidental moderno a acreditar que há, de fato, na língua, coisas como verbos, substantivos e pronomes, uma vez que esta categorização é tomada sem vir acompanhada de uma problematização de suas motivações ${ }^{1}$, a metáfora esteve presa não só à classificação de "figura de linguagem" como foi entendida como um "desvio" ao longo de décadas de pesquisa linguística moderna (se não nos mesmos termos de Aristóteles, a abordagem tem sido a mesma, com pouquíssimas variações), pelo menos até os trabalhos pioneiros de Lakoff e Johnson (1980).

Assim, mesmo que não seja o protótipo da classe gramatical, justifica-se discutir a descrição gramatical da metáfora e, principalmente, a permanência

\footnotetext{
${ }^{1}$ Devo esta observação unicamente ao professor José Borges Neto, que há anos defende a posição de que não é possível fazer uma linguística moderna sem abandonar os grilhões impostos pelas gramáticas tradicionais no que diz respeito às classes de palavras. Para ele, não faz sentido dizer que uma gramática gerativa, por exemplo, é inovadora, se não propõe uma discussão das categorias das quais as palavras fazem parte. Por outro lado, para ele, partir das classificações tradicionais torna necessária uma justificava em alguma parte do processo, ou então se abandona a tradição em favor de uma classificação que, de fato, consiga dar conta de colocar as palavras em classes de funcionamento semelhantes - ou em favor de classificação nenhuma.
} 
deste fenômeno nas gramáticas. Para tanto, traremos ao longo deste trabalho exemplos de gramáticas tradicionais e contemporâneas que ilustrem esse tipo de observação a fim de verificar se as gramáticas modernas, principalmente datadas da segunda metade do século $X X$, incluem considerações sobre este fenômeno; e, caso incluam, que tipo de coisas elas têm a dizer a respeito.

\section{Antiguidade Clássica}

Aquilo que hoje chamamos de gramática tradicional não é resultado do trabalho de apenas uma pessoa, mas de uma tradição filosófica que desembocou na preocupação com a linguagem enquanto expressão do pensamento. Assim, desde os pré-socráticos, existe um movimento para explicar, categorizar, esmiuçar o funcionamento desta capacidade que reflete muito do que se passa dentro da mente humana. As investigações linguísticas do período clássico serviram basicamente à filosofia e à lógica, até o final do século II a. C, quando os alexandrinos começaram a desenvolver uma preocupação com a língua literária, sobretudo com a manutenção da língua de Homero, naquela altura já em desuso, voltando suas considerações a um bem falar e bem escrever, em detrimento de observar a língua como elemento basilar para a filosofia. Esta virada alexandrina ecoa ainda nas gramáticas de hoje, principalmente no que diz respeito a exemplos retirados do cânone literário:

\footnotetext{
O período dos alexandrinos se destacou dos dois anteriores exatamente nesse ponto: sua preocupação com a língua era literária, e não filosófica ou lógica, e seu estudo linguístico era parte de seu estudo literário. Dois fatores contribuíram para seu interesse em estudar a língua como parte dos estudos literários: (1) o desejo de tornar accessíveis aos contemporâneos às obras de Homero, e (2) a preocupação com o "uso correto" da língua (pronúncia e gramática) a fim de preservar o grego clássico de corrupções. (GURPILHARES, 2004, p. 45).
}

A respeito da configuração das gramáticas clássicas, Gurpilhares chama a atenção para o fato de que a divisão em classes de palavras não foi sempre 
igual, mas que foram tomando forma ao longo do tempo, com diversas contribuições diferentes e reformulações, até desembocar na conhecida gramática de Dionísio da Trácia.

a) a Protágoras, sofista do séc. V a.C., deve-se a distinção dos 3 gêneros em grego;

b) a Platão (429-347 a.C) deve-se a distinção entre substantivos $x$ verbos (verbo + adjetivo);

c) a Aristóteles (384-322 a.C) deve-se o acréscimo das conjunções e a introdução do $3^{\circ}$ gênero, o intermediário, o que era chamado de nomes de "muitas coisas" (Protágoras); resultou no gênero neutro; criação da categoria de "tempo" no verbo presente e passado;

d) aos estóicos deve-se o acréscimo do "artigo", e a divisão do substantivo em: próprio/comum;

e) aos alexandrinos a criação de "paradigmas" ou "cânones" de flexão;

f) a Dionísio da Trácia, autor da $1^{a}$ gramática grega, deve-se a adição do "advérbio", do "particípio", "pronome" e "preposição". (GURPILHARES, 2004, p. 46).

Além disso, apesar de a história ter dado a Dionísio da Trácia o reconhecimento de cânone, ele também é apenas um entre toda uma geração devotada ao trabalho de regularizar as palavras em classes. Chapanski, em sua dissertação de mestrado, afirma que

A TG [Tékhne Grammatiké] de Dionisio Trácio não é, pois, a primeira gramática do ocidente. É, antes, a única de uma série de tékhnai que encontrou respaldo histórico em algum momento do tempo. Sem dúvida é a obra modelar, na qual se inspiraram gramáticos de todos os tempos, mas, em seu tempo, é possível que tenha, no entanto, não sido o modelo, mas meramente seguido um modelo, bastante comum, pré-existente. (CHAPANSKI, 2003, p. 4).

No entanto, a influência da Tékhne Grammatiké sobre a confeç̧ão de gramáticas ao longo do tempo e em diferentes línguas não pode ser menosprezada. Conforme a autora salienta, é possível que a TG tenha alcançado um reconhecimento notório na época e, então, possa ter sido imitada por outros autores, principalmente devido ao fato de que este gênero textual era bastante fechado e pouco afeito a mudanças e intervenções. O que, novamente, podemos confirmar também através da observação de gramáticas contemporâneas. 
A respeito da notoriedade do trabalho de Dionísio da Trácia, a autora afirma que

\begin{abstract}
A penetração, dos estudos gramaticais gregos, em especial do manual atribuído a Dionísio Trácio, em domínios linguísticos distintos do helênico ou helenizado, é vista como ponto de partida para a tradição dos estudos linguísticos autóctones em línguas como georgiano, armênio, siríaco e eslavônico. (VERSTEEGH, 1990, p. 198). Nesta última língua, a influência da doutrina gramatical grega se dá pelo contato vivo, interacional, dos monges eslavônicos com os monastérios bizantinos, conservadores, compiladores e produtores de uma espécie de continuação da tradição grega de estudos linguísticos. No entanto, nas demais línguas e em suas respectivas tradições gramaticais, a influência helênica se dá exclusivamente via tradução do manual dionisiano. $\mathrm{O}$ momento em que se realiza a tradução da $\mathrm{T}$. para essas línguas orientais encerra-se num período de grande produção de manuais similares, em grego e em latim, e, portanto, de notável espalhamento da doutrina gramatical técnica, manualesca: 0 século VI d. C (CHAPANSKI, 2003, p. 9).
\end{abstract}

Somando a notoriedade da TG à preocupação alexandrina com o bom uso da língua, ilustrado majoritariamente por exemplos literários, podemos formar uma figura daquilo que se convencionou chamar de gramática tradicional: basicamente, um simulacro, ou uma reescrita, a cada língua, da mesma gramática grega. Além disso, esse pensamento respalda a inclusão da metáfora nas gramáticas como figura de linguagem (como veremos posteriormente).

Pensando, então, na metáfora enquanto parte da tradição gramatical, podemos verificar que as considerações feitas a respeito dela são as mesmas desde Aristóteles e em nada diferem do que acontece com o pensamento consolidado de descrição de língua proposto pela gramática tradicional (conferir a nota 1): estamos tão acostumados a pensar daquela forma, por força da tradição, que não parece que alguém propôs aquilo um dia, mas sim que sempre se pensou daquele jeito ou que chegou-se à verdade naquele assunto: tornando-o senso comum.

Por outro lado, não é à toa que o pensamento aristotélico chegou à contemporaneidade, ainda que reformulado e, muitas vezes, disfarçado de original. Aristóteles opõe metáfora ao significado literal, postulando que as palavras possuem um sentido 'original' que pode deslizar a depender do 
contexto em que é usada. Para o filósofo, o sentido original da palavra é o que nomeia as coisas. Assim, caso a palavra não esteja nomeando aquela determinada coisa, está sendo usada 'figurativamente'. "A metáfora é a transposição do nome de uma coisa para outra, transposição de gênero para espécie, ou da espécie para o gênero, ou de uma espécie para outra, por via da analogia." (ARISTÓTELES apud OLIVEIRA, 1991, p. 9).

Em $A$ retórica, Aristóteles reformula essa definição: "Quando Homero diz de Aquiles 'que se atirou como um leão' é uma imagem; mas quando diz: 'Este leão atirou-se', é uma metáfora. Como leão e herói são ambos corajosos, por uma transposição, Homero qualificou Aquiles de leão" (ARISTÓTELES apud OLIVEIRA, 1991, p. 10). Esta é uma forma de pensar a metáfora que ecoa até hoje: determinada palavra é usada para qualificar outra por meio de um deslizamento de sentido.

Não apenas a tradição grega ecoa no tratamento da metáfora. Em algumas gramáticas, podem ser encontrados tratamentos respaldados na célebre dicotomia analogia $x$ anomalia, presente nos gramáticos latinos, especialmente Varrão. Como ilustração desta afirmação, vale o exemplo do gramático Silva Júnior (1903 apud ROCHA; CARDOSO, 2008) (ainda que tenha sido extraído de um livro intitulado Noções de Semântica, e não de sua gramática). Para este autor, a metáfora é fruto da analogia:

Uma das causas das continuas mudanças do sentido das palavras é a lei do menor esforço. O povo tem necessidade de bem exprimir idéias novas, mas afim de evitar dispêndio intellectual e ao mesmo tempo desejando apresentá-las animadas ou revestidas de cores variegadas, em vez de crear vocabulos novos, prefere - movido por essa tendência natural e espontânea - servir-se de termos já conhecidos, apenas mudando ou renovando os seus sentidos. E assim, denominaram toupeira a quem tem olhos pequenos e piscos, estendendo-se o sentido aos estúpidos e incompetentes em qualquer matéria [...]. O povo procede d'esta forma nessas transferencias sob a acção da analogia, afim de evitar qualquer dificuldade de expressão, de conseguir mais clareza, mais pôr em relevo uma opposição ou semelhança, e pelo respeito a tradição . [...] É muito conhecido o meio analógico, condição primordial da linguagem (SILVA JUNIOR, 1903 apud ROCHA; CARDOSO, 2008, p. 264). 
Este é apenas um exemplo de tratamento diferente do grego, mas com uma forma de pensar não tão afastada da questão do desvio do significado original da palavra. A seguir, veremos mais detalhadamente como essas questões afloram em algumas gramáticas de língua portuguesa.

\section{Gramáticas Tradicionais}

Para ilustrar o ponto de vista do tratamento das gramáticas tradicionais a respeito da metáfora, apresentamos aqui quatro trabalhos: Azeredo (2008), Bechara (2004), Cunha e Cintra (2001) e Lima (2000). A escolha se deu pelo fato de que todas as gramáticas possuem edições a partir do ano 2000 e, mesmo que não tenham passado por revisões em todas as edições, são um material de referência e que permanece no mercado editorial.

Lima (2000) talvez seja o mais tradicional entre os gramáticos tradicionais. Sua Gramática Normativa da Língua Portuguesa é um trabalho exemplar no que diz respeito à organização clássica de temas e da ênfase na sintaxe da língua. Ele divide sua gramática em quatro seções: i)"Fonética e Fonologia", na qual dispensa mais tempo versando sobre pronúncia e ortografia do que sobre as disciplinas-título da seção; ii) "Morfologia", na qual detalha as particularidades de cada uma das classes de palavras - substantivo, artigo, adjetivo, numeral, pronome, verbo, advérbio, preposição, conjunção, interjeição - além de fazer considerações sobre a estrutura das palavras e sobre suas regras de formação; iii) "Sintaxe", que contém considerações sobre análise sintática, bem como o emprego de cada uma das classes de palavras citadas na seção anterior, além de listas com algumas regências de verbos, notas sobre a concordância verbal, o emprego de crase, colocação de pronomes e pontuação; e iv) "Rudimentos de estilística e poética", em que o autor pretende dar uma certa aplicação dos conceitos vistos até aquele momento (como no item "valorização estilística dos fonemas") e, por fim, descreve as figuras de linguagem e dá algumas noções de versificação. 
A metáfora, o foco deste trabalho, se encontra, portanto, nesta última seção, dentro da classificação de figuras de linguagem, como "figura de palavra", junto com a metonímia. Para este autor, a metáfora "consiste na transferência de um termo para uma esfera de significado que não é sua, em virtude de uma comparação implícita." (LIMA, 2000, p. 501). Além disso, o autor salienta que a relação entre uma palavra em seu uso literal e em seu uso metafórico é facilmente percebida:

[...] assenta a metáfora numa relação de similaridade, encontrando o seu fundamento na mais natural das leis psicológicas: a associação de ideias. Assim, ela transporta o nome de um objeto a outro graças a um caráter qualquer comum a ambos: a folha da árvore dá o seu nome à folha de papel em razão da pequena espessura de uma e outra. Do mesmo modo: o fio de um discurso; onda de imigrantes; coração empedernido; cabeça de revolução; sorriso amarelo. (LIMA, 2000, p. 502).

Lima (2000) se isenta um pouco da explicação quando afirma que nem sempre é fácil encontrar o ponto de partida da metáfora, porque algumas vêm sendo usadas há tanto tempo que seu significado já não é mais metafórico, ou seja, sua originalidade se perdeu. Nesse ponto, o autor distingue dois tipos de metáfora: a estética, que "mergulha raízes na intenção deliberada de criar efeito emotivo" (LIMA, 2000, p. 502), e a linguística, que "tornada hábito da língua, já não sente nenhum vestígio de inovação criadora pessoal" (LIMA, 2000, p. 52). O autor menciona, ainda, que a tradição clássica convencionou chamar a metáfora linguística de catacrese e inclui, sob a denominação de "metáfora literária", personificação, hipérbole, símbolo e sinestesia, entendendo, acertadamente, que todas essas figuras de linguagem passam por um processo semelhante.

Azeredo, autor da Gramática Houaiss da Língua Portuguesa, também engaveta a metáfora junto com as figuras de linguagem, na sétima e penúltima parte do trabalho, intitulada "A língua e seus usos expressivos". Os outros sete capítulos tratam, respectivamente, de considerações sobre a história da gramática; língua, linguagem e comunicação, variação linguística, texto e discurso na segunda parte; dupla articulação da linguagem, relação entre 
gramática e léxico e relações sintagmáticas na terceira; morfologia flexional e sintaxe, com a apresentação das classes de palavras, análises sintáticas, períodos simples e compostos, algumas considerações sobre tempo e aspecto verbal, quadro de regências e usos na quarta seção; rudimentos de fonética e fonologia na quinta seção; considerações sobre léxico, formação de palavras e semântica lexical na sexta parte; e, por fim, um apêndice dedicado a questões de pontuação, crase e considerações sobre o vernáculo brasileiro ser diferente do de Portugal.

Se o autor parece bastante inovador na forma de apresentação dos conteúdos, privilegiando nomenclaturas advindas dos estudos linguísticos, sua apresentação da metáfora, ainda que como figura de linguagem avizinhada com outras próprias da literatura, mesmo relativamente mais completa que a feita por Lima (2000), não foge da concepção aristotélica. Azeredo é outro gramático que também apresenta a metáfora como um "princípio onipresente da linguagem, pois é um meio de nomear um conceito de um dado domínio de conhecimento pelo emprego de uma palavra usual em outro domínio" (AZEREDO, 2008, p. 484), mas salienta que "a metáfora resulta de uma operação substitutiva; a associação semântica se articula no eixo paradigmático. Trata-se de um processo que envolve termos de domínios conceituais distintos, entre os quais promove uma assimilação mental" (AZEREDO, 2008, p. 485), incorporando, ainda que muito discretamente, parte das ideias apresentadas por Lakoff e Johnson (1980).

No prefácio da 37a edição de sua gramática, Evanildo Bechara (2004) não deixa de agradecer a Eugenio Coseriu, a quem a gramática é dedicada, bem como a J. Mattoso Câmara Jr., que foi "guia seguro desde o lançamento inicial" (BECHARA, 2004, p. 19) da obra. Além disso, neste prefácio, Bechara afirma que pretende lançar mão de conceitos da linguística a fim de operacionalizar uma gramática que leve em conta o trabalho da linguística.

Bechara divide, então, sua Moderna Gramática Portuguesa em uma introdução - na qual trata rapidamente de assuntos como linguagem, norma, dialeto, história da língua, metalinguagem, diferenças entre gramáticas 
normativas e gramáticas descritivas -, e cinco seções propriamente ditas, nas quais se debruça sobre a língua portuguesa. Estas seções são, a exemplo da tradição gramatical: i) "Fonética e Fonologia", que possui observações a respeito de vogais, semivogais e consoantes, encontros vocálicos e consonantais, levando em consideração também os que causam "efeito desagradável ao ouvido" (BECHARA, 2004, p. 74), ortoepia, prosódia e ortografia; ii) "Gramática descritiva e normativa", seção na qual se debruça sobre as classes de palavras (substantivo, adjetivo, artigo, pronome, numeral, verbo, advérbio, preposição, conjunção e interjeição, exatamente nos moldes clássicos), seu emprego e suas particularidades, além de regras de formação de palavras, regência e análise sintática, sem deixar de lado as "figuras" (BECHARA, 2004, p. 592) e "vícios e anomalias de linguagem" (BECHARA, 2004, p. 598); iii) "Pontuação"; iv) "Noções elementares de estilística" e v) "Noções elementares de versificação", nas quais versa sobre teoria literária em prosa e verso.

Consoante com a proposta de modernização das gramáticas, a metáfora, por exemplo, não é apresentada juntamente com as figuras de linguagem, mas na subseção dedicada à formação de palavras, no item intitulado "Alterações semânticas". Pensar na metáfora desta forma já confere a Bechara (2004) um status de inovação, apesar das considerações extremante clássicas que tece a respeito do fenômeno:

A significação das palavras está intimamente relacionada com o mundo das ideias e dos sentimentos; 'entre as ideias, entre os pensamentos não há separação absoluta por isso que as associações se estabelecem, sem cessar, de uns para outros. Vendo uma substância ou um objeto muito achatado, muito delgado e pouco resistente, por exemplo de estanho ou de ouro finamente laminado, alguém foi levado a compará-lo a uma folha de árvore; pode-se assim dizer com propriedade e clareza: uma folha de estanho, de ouro, de papel, etc. Outra associação, posterior à precedente, deu à palavra folha o significado bem elástico de jornal: uma folha diária. É que se imprimem as notícias de cada dia em folhas de papel.' (AGr 1, 93-94 com leves adaptações para o português) (BECHARA, 2004, p. 397). 
A metáfora, então, é apenas uma das forças que atuam no sentido de modificar o significado das palavras, ao lado da metonímia, da catacrese, de eufemismo, etc. A observação mais interessante de Bechara (2004), porém, é a que segue:

\begin{abstract}
Assim, a metáfora não resulta - como tradicionalmente se diz - de uma comparação abreviada; ao contrário, a comparação é que é uma metáfora explicitada. Importa, outrossim, distinguir a metáfora linguística (linguisticamente motivada pelo descompasso dos termos implicados nas solidariedades) da metáfora motivada extralinguisticamente pelo nosso saber sobre as coisas, como ocorre em expressões metafóricas do tipo de não ponha a carroça diante dos bois para expressar a inversão incorreta de uma ação ou de um juízo. As metáforas têm largo emprego na língua espontânea e na literária, e nesta teve grande difusão entre os poetas simbolistas. (BECHARA, 2004, p. 398).
\end{abstract}

Ou seja, a metáfora usada na linguagem comum ganha um espaço maior do que nas gramáticas que a entendem, unicamente, como uma figura de linguagem listada na seção sobre versificação. Bechara (2004) possui uma intuição acertada a respeito da modificação semântica que ocorre no processo metafórico, mas, mais ainda, dá a ela um olhar diferente, aproximando-a de outros fenômenos da linguagem cotidiana.

Por fim, a Nova gramática do português contemporâneo, de Cunha e Cintra (2001), que também apresenta capítulos para cada uma das classes de palavras, além de rudimentos de fonética e fonologia, morfologia e análise sintática, bem como noções de versificação, não trata da metáfora em nenhum momento, o que pode significar um posicionamento crítico em relação ao fato de que usos literários da língua não interessam a uma classificação gramatical.

Ainda que este não seja um corpus muito extenso de gramáticas, podemos notar que todas elas, apesar de serem relativamente recentes ( $e$, mais que isso, serem editadas até os dias de hoje), apresentam uma organização clássica, apoiada na apresentação das classes gramaticais, sem propor uma discussão a respeito dos critérios que levam cada palavra a estar encaixada dentro delas, além de não abrirem espaço para as contribuições da linguística para uma possível reelaboração destas categorias. Dessa forma, por mais que os estudos linguísticos estejam subjacentes ou estejam contemplados 
nos prefácios, não há uma mudança significativa ou uma discussão mais detida acerca da categorização proposta para as palavras. A linguística, portanto, serve a uma categorização já pronta, apenas para "comprovar" o que a tradição trouxe até aqui.

Além disso, é possível ver que o tratamento da metáfora, que elencamos como escopo deste trabalho, não é inovador: exceto por Bechara (2004), que menciona o uso cotidiano deste fenômeno e o suporte necessário do nosso conhecimento de mundo (ainda que esta seja uma roupagem moderna da proposta de Aristóteles), os demais autores não parecem perceber que a metáfora não se trata apenas de uma figura de linguagem. Talvez Cunha e Cintra (2001) tenham chegado à conclusão que não é papel da gramática tradicional versar a este respeito. Esta conclusão, porém, não é suficiente nem necessária. Como veremos no item a seguir, há formas modernas de pensar a metáfora como parte de um processo linguístico que tem muito a dizer sobre o funcionamento da língua e da relação que a língua tem com o pensamento.

\section{Gramáticas Descritivas Contemporâneas}

Dentre as gramáticas escritas a partir da segunda metade do século XX, que levam em consideração descrições e análises feitas a partir de linhas de pesquisa linguística, escolhemos a Gramática de Usos do Português (NEVES, 2000) e a Nova Gramática do Português Brasileiro (CASTILHO, 2010). Estas gramáticas, por não categorizarem os fenômenos da língua da mesma forma que as gramáticas tradicionais, já apresentam uma organização de assuntos bastante diferente.

Neves (2000), que inova ao utilizar como corpus não só textos literários, mas também jornalísticos, inicia sua gramática com considerações a respeito do funcionamento de sentenças, no capítulo I, e considerações sobre textos, no capítulo II, de forma que a grande classe de pronomes

2, por exemplo, encontra-se, aqui, dividida pelas diferentes funções que 
cada palavra apresenta. Esta gramática possui ainda por um capítulo sobre quantificação antes de voltar à sentença como unidade de análise ao tratar, no capítulo V, de "junção" (seção esta que engloba preposições e conjunções).

Dessa forma, não é de causar estranhamento que a metáfora esteja presente em poucas linhas no trabalho de Neves (2000), mas o fato de estar listada como um uso especial de adjetivos. Em outras palavras, para Neves (2000, p. 199),

[...] em dependência do substantivo com o qual se constroem, os adjetivos classificadores podem passar a qualificadores, em uso metafórico, com a possibilidade de anteposição: 'Desconhecido olhava a cena tomado dum SUBTERRÂNEO temor. (N)'.

Encerram-se, aí, as considerações sobre metáfora presentes nesta gramática, o que parece ser emblemático de um pensamento que pretende tratar do funcionamento regular das sentenças, ou seja, que demonstra a adoção de um ponto de vista que pensa a metáfora não como um uso especial da língua, como queriam os tradicionais, mas algo corriqueiro. Por outro lado, causa certo estranhamento o fato de Neves (2000) mencionar que o funcionamento metafórico se dá em anteposição, visto que nem todos os adjetivos metafóricos precisam aparecer antepostos ao núcleo do sintagma (por exemplo, se a sentença fosse "Desconhecido olhava a cena tomado dum temor subterrâneo", o adjetivo qualificador não deixa de ser metafórico por estar posposto ao substantivo). De fato, a posição anteposta privilegia a interpretação metafórica calcada no uso "não corriqueiro" da metáfora, mas não o encerra.

Com isso, vemos que Neves (2000) não chega a mencionar estudos recentes sobre metáfora em sua gramática, diferentemente do que faz Castilho

\footnotetext{
2 Vale ressaltar aqui que, mesmo sendo gramáticas modernas, elas não pretendem propor uma nova nomenclatura para as classes de palavras. Dessa forma, mesmo que sejam vista sob um ponto de vista que considera o seu funcionamento, diferente das propostas das gramáticas tradicionais, as classes de palavras nessas gramáticas não recebem outros nomes. Portanto, quando utilizamos a nomenclatura "pronomes", o fazemos de acordo com a tradição vigente, esperando que este uso terminológico não nos identifique com a proposta das gramáticas tradicionais.
} 
(2010). Este autor, cuja gramática é um tratado dos trabalhos em linguística aplicados em análises de usos do português culto corrente, incorpora o ponto de vista mais moderno no que diz respeito ao tratamento da metáfora: suas propriedades conceituais e a possibilidade de haver "o entendimento de um domínio de experiência em termos de outro" e "a projeção de um conjunto de correspondências entre um domínio-fonte e um domínio-alvo" (CASTILHO, 2010, p. 132).

Castilho (2010) dá exemplos de usos tanto de metáforas cristalizadas (como vida é viagem, argumentação é guerra), como de metáforas novas. Estas, seguindo a proposta de Lakoff e Johnson (1980), o autor divide em quatro categorias: i) imagéticas, nas quais a metáfora opera com associações de imagens, como "Seus dedos eram como o teclado de um piano" (ainda que uma sentença na qual a comparativo esteja explícito não seja tratada pela literatura como metáfora, mas como comparação); ontológicas, quando as entidades são criadas pela própria metáfora, como "Não gaste seu tempo", em que a metáfora conceitual 'tempo é dinheiro' serve de base para a transformação de tempo em entidade; estruturais, quando a entidade do domínio da metáfora é concreta, como em "Ficou fervendo de raiva depois que leu a carta"; e orientadas, quando há alguma localização espacial (por exemplo, metáforas do tipo "bom é para cima", "o passado é para trás"), como "Sua renda subiu" e "Sua saúde está declinando" (CASTILHO, 2010, p. 132).

Seguida desta breve exemplificação das categorias propostas por Lakoff e Johnson (1980), o autor encerra a seção sobre metáfora da seguinte forma: "Os estudos de Lakoff e Johnson (1980, 2002) mostraram que na criação de metáforas podemos associar dois ou mais domínios, e com isso obtemos metáforas primitivas ou metáforas compostas. De todo modo, o móvel da alteração do sentido está fora do texto" (CASTILHO, 2010, p. 132), do que se depreende que a metáfora, portanto, não é uma categoria gramatical, em princípio, e que seu funcionamento não estaria contemplado em análises que privilegiam uma sentença isoladamente. 


\section{Metáfora em Outras Categorias Gramaticais: Preposição}

Esta não é, porém, a única forma possível de encarar os fatos. Apesar de ser extremamente vanguardista incorporar um tratamento linguístico da metáfora em sua gramática, Castilho passa despercebido por um aspecto interessante do funcionamento dela: sob o nosso ponto de vista, é possível admitir que a metáfora seja um processo regular que pode estar presente nos processos gramaticais.

Antes disso, cabe trazer a essa discussão a proposta de Pinker (2008). Para este autor, que incorpora e amplia as considerações de Kant (1781 apud PINKER, 2008), temos acesso à realidade por meio de quatro categorias que se manifestam na forma com que a língua está organizada. Estas categorias seriam substância, espaço, tempo e causalidade. Para fins deste trabalho, vamos nos ater especificamente às noções de espaço e tempo, e na forma como as duas se entrelaçam.

Como Lakoff e Johnson (1980), Pinker (2008) assume que nossa mente está sujeita à experiência corporal que temos para categorizar nosso pensamento - e, de quebra, manifestar essa organização em termos linguísticos. Para a organização mental de tempo, por exemplo, partiríamos de nossas experiências concretas como nosso relógio biológico (e mesmo o passar do dia, o nascer e o por do sol ou a mudança das estações do ano) e chegaríamos ao enquadramento de processos abstratos, como noções de passado e futuro e expressão de tempos verbais, por exemplo. Ou seja, se falamos sobre coisas abstratas, é porque incorporamos a experiência física e modificamos sua percepção para que nossa mente pudesse categorizar estes processos abstratos por meio da língua.

Com base nesse tipo de enquadramento, Pinker (2008) relaciona, então, formas e expressões linguísticas para fazer a correspondência entre as categorias mentais de Kant e a linguagem que usamos no dia a dia; assim, nossa noção de espaço seria expressa por meio de preposições e a noção de tempo, por meio dos tempos verbais. 
Uma percepção interessante de Pinker (2008) diz respeito à forma como nossa mente captura e interpreta os objetos do mundo. Assim, por algum mecanismo cognitivo, salientamos alguma dimensão do objeto em questão (em geral, a mais relevante) e não nos referimos a eles como sendo dotados de três dimensões (ainda que sejam!), mas como um modelo esquemático. Segundo este autor, entre diversas outras formas, isso fica evidente na seleção de preposições que fazemos quando falamos destes objetos.

Exemplos não faltam: um lago, segundo o autor, tem comprimento, largura e profundidade. Mas as três dimensões não emergem, no entanto, quando falamos "nadei ao longo do lago" ou "nadei através do lago", como se o lago em questão tivesse apenas comprimento ou largura; ao contrário, ninguém diria "nadei dentro do lago", embora isso fosse mais preciso em termos espaciais. Além disso, alguém que dissesse "um cd grande" estaria se referindo ao diâmetro do cd (talvez à sua capacidade de memória), e não à sua espessura, e de nenhuma forma isso soaria ambíguo.

A parte mais interessante, porém, está na consideração sobre o fato de as preposições serem extremamente vagas, e de podermos usá-las independentemente do tipo de lugar ou do tipo de indivíduo referido (podemos dizer tanto "viajamos através do país", e "através" significa muitos quilômetros, ou "a bolinha passou através da janela", e a mesma preposição denotaria centímetros). Além disso, nisso reside uma interessante constatação: podemos usar as mesmas palavras para nos referirmos ao espaço e ao tempo. A explicação disso, para Pinker (2008), está no fato de que pensamos no tempo como sendo dimensional (ainda que com apenas uma dimensão). Para Lakoff e Johnson (1980), isto está relacionado com as experiências físicas pelas quais passamos e das quais abstraímos formas de relacionar.

Nesse ponto da discussão, vale a pena esmiuçar as metáforas orientacionais de Lakoff e Johnson (1980 apud Castilho (2010, p. 15):

Até agora, nós examinamos o que chamamos de metáforas estruturais, casos nos quais um conceito é metaforicamente estruturado em termos de outro. Mas existe outro tipo de conceito metafórico, que não estrutura um conceito em termos de outro, mas, 
ao invés disso, organiza um sistema de conceitos inteiro em relação com outro. Chamaremos estas de metáforas orientacionais, já que a maioria delas tem a ver com orientação espacial: cima-baixo, frentetrás, ligado-desligado, profundo-raso, central-periférico. ${ }^{3}$

Para estes autores, isto emerge do fato de que temos corpos (simétricos apenas bilateralmente) que estão inseridos em um meio e que nossa experiência vem do funcionamento deles. Evidentemente, determinados aspectos diferem de uma cultura para outra, mas há regularidades que são, sem dúvida, instigantes.

Os autores apontam exemplos deste tipo de metáfora e sugerem determinadas explicações para sua origem ou plausibilidade. Assim, a orientação metafórica "feliz é para cima; triste é para baixo" (manifestada em sentenças como "Estou me sentindo para cima hoje", "Isto elevou meu astral", "Pensar nele sempre me dá uma levantada", "Estou me sentindo para baixo", "Estou deprimido", "Meu ânimo afundou') seria baseada no fato de que deixar a postura caída é, em geral, uma manifestação de tristeza e desânimo, ao contrário de uma postura ereta, que geralmente indica um estado emocional positivo (LAKOFF; JOHNSON, 1980, p. 15). Já as orientações "saúde e vida são para cima, doença e morte são para baixo" (manifestadas em sentenças como "Ele está no topo da saúde", "Lázaro levantou da morte", "Ele caiu doente", "Ele está afundando rápido", "Ele caiu morto") seriam baseadas no fato de que doenças sérias fazem as pessoas ficarem deitadas e, quando mortos, estamos inclusive debaixo da terra ("fisicamente para baixo"), nas palavras de Lakoff e Johnson (1980).

Desse tipo de associação (feliz e saudável são para cima, triste, doente e morto são para baixo), emergem também outras associações metafóricas espaciais, como "melhor posição social é para cima", "controle e poder são para cima", "bom é para cima", "virtude é para cima" e, ainda, "racionalidade é para

\footnotetext{
${ }^{3}$ So far we have examined what we will call structural metaphors, cases where one concept is metaphorically structured in terms of another. But there is another kind of metaphorical concept, one that does not structure one concept in terms of another but instead organizes a whole system of concepts with respect to one another. We will call these orientational metaphors, since most of them have to do with spatial orientation: up-down, in-out, frontback, on-off, deep-shallow, central-peripheral.
} 
cima" (principalmente associada ao fato de que ter controle é ter poder e que o controle é o que torna o tipo de mente racional mais prestigiada), com as oposições "pior posição social é para baixo", "ser controlado é para baixo", "ruim é para baixo", "depravação é para baixo" e "emoção é para baixo".

Para estes autores, a maioria dos conceitos fundamentais da língua está organizada dessa forma e, no seu ponto de vista, há uma grande sistematicidade das metáforas espacialmente orientadas, no sentido de que elas são bastante coerentes e consistentes, ainda que sua orientação não seja fundamentada apenas no aspecto físico, mas apoiada em alguma atribuição de valor cultural (por exemplo, "saúde é para cima", aparentemente, é motivada fisicamente, enquanto "poder é para cima" e "racionalidade é para cima" podem estar ligadas a valores de diferentes culturas).

Sobre a coerência interna do sistema, os autores afirmam que:

\begin{abstract}
Existem muitas bases físicas e sociais possíveis para a metáfora. A coerência dentro do sistema parece ser uma parte da razão pela qual uma [metáfora] é escolhida e não outra. Por exemplo, a felicidade também tende a ser correlacionada fisicamente com um sorriso e um sentimento geral de expansividade. Isto poderia, em princípio, formar a base para a metáfora FELIZ É LARGO; TRISTE É ESTREITO. E há, de fato, expressões metafóricas menores, como "Estou me sentindo expansivo", que seleciona aspectos diferentes de felicidade do que "Estou me sentindo para cima" faz. Mas a maior metáfora em nossa cultura é FELIZ É PARA CIMA; existe uma razão pela qual nós falamos sobre a altura do êxtase e não sobre a largura do êxtase. FELIZ É PARA CIMA é mais coerente com BOM É PARA CIMA, SAUDÁVEL É PARA CIMA, etc. (LAKOFF; JOHNSON, 1980, p. 18). ${ }^{4}$
\end{abstract}

Isto não significa que sejam claros os limites entre o que é uma base cultural e o que é uma base física para a metáfora. Para os autores, "é difícil distinguir entre uma forma física e uma base cultural da metáfora, uma vez que

\footnotetext{
${ }^{4}$ There are many possible physical and social bases for metaphor. Coherence within the overall system seems to be part of the reason why one is chosen and not another. For example, happiness also tends to correlate physically with a smile and a general feeling of expansiveness. This could in principle form the basis for a metaphor HAPPY IS WIDE; SAD IS NARROW. And in fact there are minor metaphorical expressions, like "I'm feeling expansive," that pick out a different aspect of happiness than "I'm feeling up" does. But the major metaphor in our culture is HAPPY IS UP; there is a reason why we speak of the height of ecstasy rather than the breadth of ecstasy. HAPPY IS UP is maximally coherent with GOOD IS UP, HEALTHY IS UP, etc.
} 
a escolha de uma base física entre muitas outras possíveis tem a ver com a coerência cultural." (LAKOFF; JOHNSON, 1980, p. 18). ${ }^{5}$

Do que temos visto até agora, podemos salientar que: i) há uma relação imbricada entre o que apreendemos da realidade por meio da nossa mente e a forma com que nos referimos a ela por meio da língua e ii) a metáfora reside não só em nomes e verbos transferidos de domínios, mas também na forma como organizamos as relações entre as coisas (ou seja, naquilo que a gramática tradicional convencionou chamar de preposições e conjunções).

\section{Considerações Finais}

Com base em tudo o que viemos discutindo até aqui, podemos perceber que há tentativas de romper com a gramática tradicional, mas que esse rompimento está se dando a passos lentos, sem o abandono de uma tradição para a instauração de outra. De fato, não se esperaria mais que isso do vanguardismo dos autores da segunda metade do século XX. Dessa forma, Castilho (2010) pode ser considerado extremamente inovador na inclusão do tratamento da metáfora proposto por Lakoff e Johnson (1980), não só por este ser um trabalho voltado a pensar no fenômeno de uma forma diferente, mas pelo fato de tirar o ranço da metáfora como uso linguístico circunscrito à literatura.

Reconhecido o mérito do autor, no entanto, fazemos uma ressalva, que ficou clara no item anterior: Castilho (2010) poderia ter ido um pouco além e mostrado que palavras de diversas classes podem ser usadas metaforicamente, algumas mesmo como metáforas feitas por associações da nossa própria mente (como é o caso das espacialmente orientadas, manifestadas, por vezes, nas preposições que utilizamos).

\footnotetext{
${ }^{5}$ It is hard to distinguish the physical from the cultural basis of a metaphor, since the choice of one physical basis from among many possible ones has to do with cultural coherence.
} 
Dizemos isso por entendermos que, apesar de certas metáforas orientacionais serem culturais, isso não impede o fato de que figurem como um mecanismo gramatical interessante, porque é regular e porque podemos gerar metáforas deslocando termos usados para referir a tempo para nos referimos a espaço e vice-versa (como "A escola está a dez minutos daqui"). O que é idiossincrático de cada cultura, portanto, pode tranquilamente figurar em uma gramática, uma vez que esta vai tratar apenas de uma língua, ainda que possa englobar diversas variedades.

Por fim, este trabalho pretende advogar que a metáfora, caso seja inserida em uma gramática, não precisa estar reduzida a um fenômeno literário ou de uso rebuscado da língua, em uma seção no capítulo final, mas pode figurar como um mecanismo produtivo e interessante no que diz respeito a dar pistas do nosso funcionamento cognitivo. Assim, a metáfora pode ser vista como um mecanismo pelo qual palavras ampliam seu significado, se relacionam umas com as outras (com relações nem sempre tão claras como pretendiam os nossos gramáticos), se misturam e passam a fazer parte do significado consolidado de outras. Se é verdade que nossa mente realiza processos de abstração a partir de coisas concretas e manifesta isso na linguagem, a gramática poderia despertar o interesse de leigos a pensar nesse tipo de coisa.

\section{Referências}

ARISTÓTELES. Arte poética. Tradução de Eudoro de Souza. São Paulo: Ars Poetica, 1993.

AZEREDO, José Carlos. Gramática Houaiss da língua portuguesa. 2. ed. São Paulo: Publifolha, 2008.

BECHARA, Evanildo. Moderna gramática portuguesa. 37. ed. Rio de Janeiro: Lucerna, 2004.

CASTILHO, Ataliba de. Nova gramática do português brasileiro. São Paulo: Contexto, 2010.

CHAPANSKI, Gissele. Uma tradução da Tékhne Grammatiké de Dionísio Trácio para o português. 2003. 190 f. Dissertação (Mestrado em Letras) - Universidade Federal do Paraná, Curitiba, 2003. Disponível em: <http://dspace.c3sl.ufpr.br/ 
dspace/bitstream/handle/1884/24818/D\%20-\%20CHAPANSKI\%2c\%20 GISSELE.pdf?sequence=1>. Acesso em: 23 fev. 2013.

CUNHA, Celso; CINTRA, Lindley. Nova gramática do português contemporâneo. 3. ed. Rio de Janeiro: Nova Fronteira, 2001.

GURPILHARES, Marlene Silva Sardinha. As bases filosóficas da gramática normativa: uma abordagem histórica. Janus, Lorena, v. 1, n. 1, p. 41-51, 2004. Disponível em: <http://www.publicacoes.fatea.br/index.php/janus/ article/view/10/9>. Acesso em: 23 fev. 2013.

LAKOFF, George; JOHNSON, Mark. Metaphors we live by. Chicago: University Press, 1980.

LAKOFF, George; JOHNSON, Mark. Philosophy in the flesh. Cambridge: MIT Press, 2000.

LIMA, Carlos Henrique da Rocha. Gramática normativa da Língua portuguesa. 39. ed. Rio de Janeiro: José Olympio, 2000.

NEVES, Maria Helena de Moura. Gramática de usos do português. São Paulo: Unesp, 2000.

OLIVEIRA, Roberta Pire. As faces do rosto. 1991. 186 f. Dissertação (Mestrado) - Unicamp, Campinas, 1991. Disponível em: <http://tinyurl.com/63onaxu>. Acesso em: 22 fev. 2013.

PINKER, Steven. Do que é feito o pensamento: a língua como janela para a natureza humana. São Paulo: Companhia das Letras. 2008.

ROCHA, Maria Bernadete; CARDOSO, Maria Lúcia. A permanência da gramática latina na gramática científica brasileira. In: SEC, 23., 2008, Araraquara. Anais... Araraquara: Unesp, 2008. Disponível em: <http://portal.fclar.unesp.br/ec/ BANCO\%20DE\%20DADOS/XXIII\%20SEC/TEXTOS/ARTIGOS\%20PDF/rocha.pdf>. Acesso em: 23 fev. 2013. 